\title{
From $Z$ to A: Putting Zika virus in perspective
}

\author{
Jun Teruya, MD, DSc, ${ }^{a, b}$ and James Versalovic, $\mathrm{MD}, \mathrm{PhD}^{\mathrm{a}, \mathrm{b}}$
}

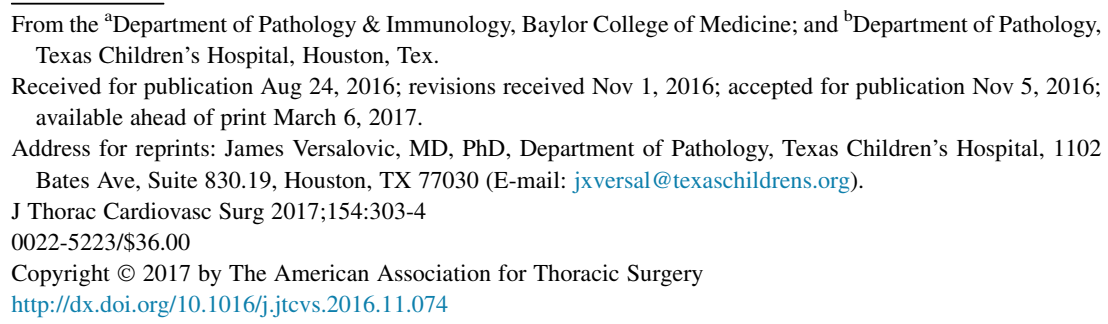

From the ${ }^{\mathrm{a} D e p a r t m e n t ~ o f ~ P a t h o l o g y ~ \& ~ I m m u n o l o g y, ~ B a y l o r ~ C o l l e g e ~ o f ~ M e d i c i n e ; ~ a n d ~}{ }^{\mathrm{b}}$ Department of Pathology, Texas Children's Hospital, Houston, Tex.

Received for publication Aug 24, 2016; revisions received Nov 1, 2016; accepted for publication Nov 5, 2016; available ahead of print March 6, 2017

Address for reprints: James Versalovic, MD, PhD, Department of Pathology, Texas Children's Hospital, 1102 Bates Ave, Suite 830.19, Houston, TX 77030 (E-mail: jxversal@texaschildrens.org).

J Thorac Cardiovasc Surg 2017;154:303-4

$0022-5223 / \$ 36.00$

Copyright (c) 2017 by The American Association for Thoracic Surgery

http://dx.doi.org/10.1016/j.jtcvs.2016.11.074

Reports of Zika virus infections in South Florida caused by mosquito-borne transmission and travel-associated infections across the United States have stirred intense interest about the epidemiology of this virus. Zika virus, a flavivirus, was first documented as a cause of human infection in Nigeria in 1954. The range of Zika virus expanded gradually eastward from Africa to Southeast Asia to the South Pacific and has been reported to cause disease outbreaks since 2007 in French Polynesia.

Two phylogenetic lineages (African and Asian/Pacific) of Zika virus have emerged, and the New World Zika virus is related most closely to viral isolates from the Asian/Pacific lineage. Human Zika virus infections have surged in South America, notably Brazil, since May 2015, and have been reported in Africa, Asia, and the Americas. Like chikungunya, dengue, and yellow fever viruses, Zika virus is transmitted actively by 2 daytime-active mosquito species, Aedes aegypti and the tiger mosquito, Aedes albopictus.

It is worth noting that flaviviruses are well documented in the modern history of the Americas. Yellow fever virus was prevalent widely in Latin America by the late 1800s, and yellow fever had a major impact on the construction of the Panama Canal. Yellow fever virus re-emerged recently in Angola and continues to cause infections in the Americas. Dengue surged in incidence recently in the Americas, and dengue virus caused record numbers of documented infections in Brazil in 2015. A single case of dengue recently was confirmed in Key West, Florida, in 2016 after dengue outbreaks there in 2009 and 2010. Of interest to thoracic and cardiovascular surgery, dengue virus may cause myocardial impairment and rarely, fulminant myocarditis. ${ }^{1}$ Dengue is an important consideration because its expansion in case numbers has occurred during the same period of time that Zika virus has emerged in the Western Hemisphere. Dengue-Zika virus coinfection may cause increased disease severity while spreading viral infections via common mosquito vectors.

Zika virus is asymptomatic in the majority of infected individuals, making it challenging to diagnose. Symptoms

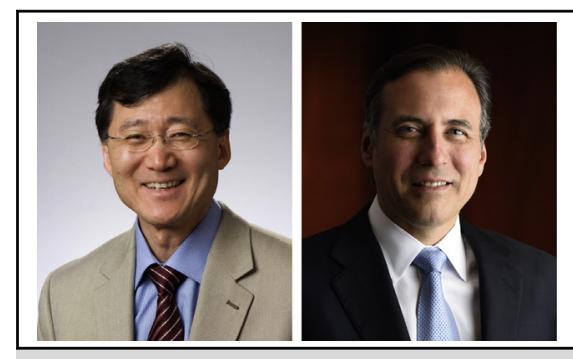

Jun Teruya, MD, DSc, and James Versalovic, MD, PhD

Central Message

Zika virus has spread rapidly in the Americas and may cause microcephaly and neurologic complications. Surgeons should be aware of possible transfusion-transmitted Zika virus infections.

See Editorial Commentary page 305

of Zika virus infection include fever, headache, arthralgia, myalgia, and maculopapular rash. Zika virus can be transmitted vertically from mother to infant, with devastating consequences for the neurologic development of the fetus. Microcephaly is a hallmark outcome if the infection occurs in the first or second trimesters of pregnancy. $^{2,3}$ The impact of postnatal infection, even during infancy, on cranial or brain development is not clear. In Africa, Zika virus has not been associated with neurologic sequelae such as Guillain-Barré syndrome (GBS) or microcephaly in the infant. Zika virus of the Asian/Pacific lineage was first associated with cases of $\mathrm{GBS}^{4}$ and the Asian/Pacific lineage was associated with many cases of microcephaly in Brazil. Regarding GBS and Zika virus, individuals may present 1 week or longer after exposure to the virus, and in one report only $56 \%$ of patients with GBS post-Zika virus infection were capable of walking without assistance 3 weeks after their care. ${ }^{4}$

As Zika virus continues to expand via mosquito-borne transmission, rapid diagnostics of Zika virus infection are a priority. Zika virus can be transmitted in 4 ways: via Aedes mosquitoes, vertical transmission during pregnancy, sexual transmission, or blood transfusion. Acute infection can be detected rapidly in blood when nucleic acid amplification is performed to detect gene(s) in the RNA viral genome. Although Zika viremia (blood detection) likely lasts for a maximum period of 1 to 2 weeks, other sample types such as human urine can extend the period of direct viral 
detection to 2 to 3 weeks after primary infection. In addition to targeting viral genomes, serum antibody testing can be quite useful for documenting recent or past infections. Beyond the acute phase, serum antibody (IgM and $\operatorname{IgG}$ ) testing is essential for the diagnosis of recent or past Zika virus infection and counseling of families at risk for vertical and sexual transmission. A positive IgM result indicates recent and perhaps active infection beyond the window of direct Zika virus detection. Molecular and serologic tests also may distinguish Zika virus from other flaviviruses in patients.

With respect to blood transfusions that may be required for surgical management, flaviviruses such as dengue and West Nile virus have been documented to cause transfusion-associated virus infections. The possible risk of Zika virus transmission via blood transfusion was first considered after $2.8 \%$ of asymptomatic blood donors tested positive for Zika virus RNA in French Polynesia. ${ }^{5}$ No evidence of transfusion-associated Zika virus infection has been found to date in French Polynesia. Careful monitoring should continue for up to 6 months after transfusion. Transmission of Zika virus via blood transfusion has been documented in Brazil. ${ }^{6}$ Beginning in February 2016, blood donor centers in the United States adopted a new policy for donor selection with regard to risk factors for Zika virus infection. Risk factors include travel to a Zika-endemic region or sexual contact with a man who has resided in or traveled to a Zika endemic region.

In August 2016, the Food and Drug Administration announced recommendations that all donor units collected in the United States and its territories should be tested for Zika virus with an investigational (or licensed) individual donor nucleic acid test. Currently, at least 2 tests are available for RNA-based screening of Zika virus under investigational new drug/device protocols by some U.S. blood centers. Alternatively, implementation of pathogen-reduction technologies may be adopted for platelets and plasma. Of note, this technology has not been approved for red cell units. Once the recommendations are implemented, blood donor centers may discontinue screening donors for Zika risk factors as mentioned previously. ${ }^{7}$ The AABB is providing regular updates regarding Zika virus and monitoring of the U.S. blood supply by direct molecular testing. ${ }^{8}$

In summary, medical centers throughout the Americas must be prepared to assess and diagnose patients with Zika virus infection rapidly. Current geographic ranges of Aedes mosquito vectors and prevention strategies should be considered when advising families regarding travel, family planning, and risk of infection. Little is known about Zika virus infection in the posttransplantation setting, and flavivirus infection, including Zika virus, in the immunocompromised host is a fertile area for future research efforts. Blood components and transfusion practices should be carefully reviewed and monitored to assure the safety of the blood supply with respect to Zika virus.

\section{Conflict of Interest Statement}

J.V. receives unrestricted research support from BioGaia $\mathrm{AB}$. The other author has nothing to disclose with regard to commercial support.

\section{References}

1. Yacoub S, Wertheim H, Simmons CP, Screaton G, Wills B. Cardiovascular manifestations of the emerging dengue pandemic. Nat Rev Cardiol. 2014;11: $335-45$.

2. Rubin EJ, Greene MF, Baden LR. Zika Virus and microcephaly. $N$ Engl J Med. 2016;374:984-5.

3. Mlakar J, Korva M, Tul N, Popović M, Poljšak-Prijatelj M, Mraz J, et al. Zika virus associated with microcephaly. N Engl J Med. 2016;374:951-8.

4. Cao-Lormeau VM, Blake A, Mons S, Lastère S, Roche C, Vanhomwegen J, et al. Guillain-Barré Syndrome outbreak associated with Zika virus infection in French Polynesia: a case-control study. Lancet. 2016;387:1531-9.

5. Musso D, Nhan T, Robin E, Roche C, Bierlaire D, Zisou K, et al. Potential for Zika virus transmission through blood transfusion demonstrated during an outbreak in French Polynesia, November 2013 to February 2014. Euro Surveill. 2014;19: 20761.

6. Barjas-Castro ML, Angerami RN, Cunha MS, Suzuki A, Nogueira JS, Rocco IM, et al. Probable transfusion-transmitted Zika virus in Brazil. Transfusion. 2016;56: 1684-8.

7. U.S. Food and Drug Administration. Revised Recommendations for Reducing the Risk of Zika Virus Transmission by Blood and Blood Components. Available at: https://www.fda.gov/downloads/BiologicsBloodVaccines/GuidanceCompliance RegulatoryInformation/Guidances/Blood/UCM518213.pdf. Accessed February 28, 2017.

8. AABB. Zika Virus: Overview. Available at: http://www.aabb.org/advocacy/ regulatorygovernment/donoreligibility/zika/Pages/default.aspx. Accessed February $28,2017$. 